\title{
Combining plant volatiles and pheromones to catch two insect pests in the same trap: Examples from two berry crops
}

\author{
C.A. Baroffio ${ }^{\mathrm{a}, *}$, L. Sigsgaard ${ }^{\mathrm{b}}$, E.J. Ahrenfeldt ${ }^{\mathrm{b}}$, A.-K. Borg-Karlson ${ }^{\mathrm{c}}$, S.A. Bruun ${ }^{\text {g,h }}$, J.V. Cross ${ }^{\mathrm{d}}$, \\ M.T. Fountain ${ }^{\mathrm{d}}$, D. Hall ${ }^{\mathrm{e}}$, R. Mozuraitis ${ }^{\mathrm{c}}$, B. Ralle ${ }^{\mathrm{f}}, \mathrm{N}$. Trandem $^{\text {g,h }}$, A. Wibe ${ }^{\mathrm{i}}$ \\ a Agroscope, Rte des Eterpys 18, 1964 Conthey, Switzerland \\ ${ }^{\mathrm{b}}$ University of Copenhagen, Department of Plant and Environmental Sciences, Thorvaldsensvej 40, DK-1871 Frederiksberg C, Denmark \\ ${ }^{\mathrm{c}}$ KTH Royal Institute of Technology, Department of Chemistry, SE-10044 Stockholm, Sweden \\ d NIAB EMR, New Road, Kent ME19 6BJ, UK \\ e Natural Resources Institute, University of Greenwich, Central Avenue, Chatham Maritime, Kent, ME4 4TB, UK \\ ${ }^{\mathrm{f}}$ LPPRC Latvian Plant Protection Research Centre, Struktoru lela 14 a, Riga, LV-1039, Latvia \\ ${ }^{\mathrm{g}}$ NIBIO Norwegian Institute of Bioeconomy Research, NO-1431 Ås, Norway \\ ${ }^{\mathrm{h}}$ NMBU Norwegian University of Life Sciences, Faculty of Environmental Sciences and Natural Resource Management, NO-1432 Ås, Norway \\ ${ }^{\mathrm{i}}$ NORSØK Norwegian Centre for Organic Agriculture, Gunnars vei 6, NO-6630 Tingvoll, Norway
}

\section{A R T I C L E I N F O}

\section{Keywords:}

Strawberry

Raspberry

Anthonomus rubi

Lygus rugulipennis

Byturus tomentosus

Semiochemical trap

\begin{abstract}
A B S T R A C T
Most horticultural crops are attacked by more than one insect pest. As broad-spectrum chemical control options are becoming increasingly restricted, there is a need to develop novel control methods. Semiochemical attractants are available for three important horticultural pests, strawberry blossom weevil, Anthonomus rubi Herbst (Coleoptera: Curculionidae), European tarnished plant bug, Lygus rugulipennis Poppius (Hemiptera: Miridae) and raspberry beetle, Byturus tomentosus deGeer (Coleoptera: Byturidae). Traps targeting more than one pest species would be more practical and economical for both monitoring and mass trapping than traps for single-species. In this study we aimed to (1) improve the effectiveness of existing traps for insect pests in strawberry and raspberry crops by increasing catches of each species, and (2) test if attractants for two unrelated pest species could be combined to capture both in the same trap without decreasing the total catches. Field tests were carried out in four European countries and different combinations of semiochemicals were compared. A volatile from strawberry flowers, 1,4 dimethoxybenzene (DMB), increased the attractiveness of the aggregation pheromone to both sexes of $A$. rubi. The host-plant volatile, phenylacetaldehyde (PAA), increased the attraction of female $L$. rugulipennis to the sex pheromone, and, in strawberry, there was some evidence that adding DMB increased catches further. Traps baited with the aggregation pheromone of $A$. rubi, DMB, the sex pheromone of $L$. rugulipennis and PAA attracted both target species to the same trap with no significant difference in catches compared to those single-species traps. In raspberry, catches in traps baited with a combination of $A$. rubi aggregation pheromone, DMB and the commercially available lure for B. tomentosus, based on raspberry flower volatiles, were similar to those in single-species traps. In both crops the efficiency of the traps still needs improvement, but the multispecies traps are adequate for monitoring and should not lead to confusion for the user as the target species are easy to distinguish from each other.
\end{abstract}

\section{Introduction}

Knowledge of insect behavioural responses to combinations of semiochemicals can be used in new approaches to monitoring and trapping insect pests (Lindgren, 1983; Oelschlager et al., 1995; Suckling, 2000; Alpizar et al., 2002; El Sayed et al., 2006; Nakashima et al., 2016). Pheromone traps are already used in fruit growing areas world-wide to monitor insect pests (Tingle and Mitchell, 1975;
Suckling, 2000; Schlyter et al., 2001; Nakashima et al., 2016) but plant volatiles can potentially enhance or inhibit the response to speciesspecific sex or aggregation pheromones (Landolt and Phillips, 1997). The challenges are to determine the optimal blend of plant volatiles (Bruce and Pickett, 2011) and of plant volatiles and pheromones (Fountain et al., 2017; Saïd et al., 2005).

In European berry crops, plant volatiles and pheromones acting as attractants have been found for several important pest species,

\footnotetext{
* Corresponding author.

E-mail address: catherine.baroffio@agroscope.admin.ch (C.A. Baroffio).
} 
including strawberry blossom weevil, Anthonomus rubi Herbst (Coleoptera, Curculionidae), (Wibe et al., 2014a), European tarnished plant bug, Lygus rugulipennis Poppius (Heteroptera, Miridae) (Fountain et al., 2014) and raspberry beetle, Byturus tomentosus DeGeer (Coleoptera, Byturidae) (Birch et al., 2009).

Anthonomus rubi is an important pest in strawberries and raspberries in northern and central Europe (Trandem et al., 2004). It overwinters as an adult and becomes active in April (Stäubli and Höhn, 1989). It feeds on leaves and flowers for two to three weeks, after which the females oviposit into flower buds and sever the petioles to protect the eggs. Each female can lay more than 150 eggs (Easterbrook et al., 2003). The larval and pupal stages develop in the cut buds. Lygus rugulipennis feeds on a wide range of plants and is a pest on many crops. The piercing mouthparts of nymphs and adults cause fruit distortion in up to $80 \%$ of berries (Cross et al., 2011; Fitzgerald and Jay, 2011). The bug overwinters as an adult with one to two generations in northern and central Europe. Byturus tomentosus overwinters as an adult, beginning activity in April and mating in May in central Europe (Antonin, 1984). In Northern Scandinavia, the beetle may need two years to complete a generation (Stenseth, 1974). Females lay an average of 100 eggs singly in flowers or young fruitlets with an average of 1-3 eggs per day (Antonin, 1984). Damage is caused by larval development in fruits, and the tolerance of retailers is often zero, i.e. fruit consignments are rejected if one larva is found (Schmid et al., 2006).

These three pests are commonly controlled using broad-spectrum chemical insecticides that may have negative impacts on the environment, non-target insects and human health, and their use is increasingly restricted (Hillocks, 2012). Furthermore, A. rubi is developing resistance to insecticides (Aasen and Trandem, 2006), limiting the effect of chemical control. There is also a high demand from consumers for fruits without pesticide residues (Tamm et al., 2004; Cross and Berrie, 2006). Thus growers, especially organic growers who have few effective measures against such pest insects, require alternative methods for pest management. The use of traps baited with attractants can be part of a control strategy aimed at managing pest insects without using synthetic insecticides. This has previously been shown for the boll weevil, Anthonomus grandis grandis (Boheman) in U.S. cotton, where pheromone trapping has been important both for monitoring and control (Ridgway et al., 1990).

Innocenzi et al. (2001, 2002) identified four components of the male-produced aggregation pheromone of $A$. rubi, and the lure was further optimized by Cross et al. (2004; 2006a, 2006b). More recently, Wibe et al. (2014a) reported that addition of 1,4-dimethoxybenzene, a component of the volatiles from the flowers of wild varieties of strawberry, increased the attractiveness of the pheromone blend to $A$. rubi.

Components of the female-produced sex pheromone of L. rugulipennis were identified as hexyl butyrate, $(E)$-2-hexenyl butyrate and $(E)$ 4-oxo-2-hexenal by Innocenzi et al. (2005). A precise blend of these chemicals released from specially-developed dispensers was shown to attract males to traps in the field (Fountain et al., 2014). An effective trap should also attract females, as do aggregation pheromones and plant volatiles (El-Sayed et al., 2006). Frati and Salerno (2008) found that both males and females of $L$. rugulipennis were strongly attracted to host plants with conspecific females in laboratory bioassays, suggesting that host-plant volatiles increased the attractiveness of the pheromone. Some of these volatile compounds were identified and phenylacetaldehyde (PAA) was shown to increase the attractiveness of the sex pheromone (Frati et al., 2009; Koczor et al., 2012).

Byturus tomentosus uses both visual and olfactory cues to locate raspberry flowers (Woodford et al., 2003), and two volatile components (RV) of the raspberry flower odour plume are particularly attractive (Woodford et al., 2003). A trap based on the most attractive blend was developed in Scotland and tested in Scotland, Norway and Switzerland (Birch et al., 2009; Trandem et al., 2009; Baroffio and Mittaz, 2011; Baroffio et al., 2012).
Currently, the semiochemical traps are only used for monitoring these three pests, but they have potential for controlling the pests by mass trapping if they can be further optimized. For example, by adding plant volatiles female insects searching for egg-laying sites may be attracted and trapped, thereby reducing crop damage (Wibe et al., 2014b; Fountain et al., 2015; Trandem et al., 2015). Also, insect traps would be more cost effective if each trap attracted more than one pest species, reducing the material and labour costs of maintaining separate traps for each pest (Wibe et al., 2012). Such combination traps are feasible if the semiochemicals used to attract one target species do not significantly reduce the attractiveness of those for another species. Insect pheromones are species-specific and interference between pheromones is unlikely as Smit et al. (1997) demonstrated for sweet potato weevils, Cylas puncticollis (Boheman) and C. brunneus (Fabricius) (Coleoptera: Curculionidae). However, adding plant volatiles to a pheromone may disrupt the behavioural response of the insects to the pheromone (Wang et al., 2016).

In the present field studies we aimed to (1) improve the effectiveness of existing monitoring insect traps in strawberry and raspberry by increasing catches of both sexes of the three target species, and (2) to demonstrate that two unrelated pest species could be attracted by semiochemicals to the same trap without decreasing the total catches. The possible influence of background volatiles on trapping success (Cai et al., 2017; Knudsen et al., 2017), made it preferable to carry out experiments in the field rather than the laboratory.

\section{Materials and methods}

The experiments were carried out during 2013 and 2014 in UK, Denmark, Norway and Switzerland (see Table 1). For the strawberry pests, $A$. rubi and $L$. rugulipennis, semiochemical blends targeting single species were tested in 2013, and in 2014 the concept of a single trap targeting two species was tested. For the raspberry pests, $A$. rubi and $B$. tomentosus, semiochemical blends had already been tested separately in previous studies (Baroffio et al., 2012; Wibe et al., 2014b) and thus the concept of using a single trap for the two species was studied in both years.

\section{Traps}

In all experiments green funnel traps (Unitrap) with cross-vanes were used (Agrisense, Treforest, Pontypridd, UK, and Sentomol, Glen House, Monmouth, UK). These traps consisted of a bucket $(16 \mathrm{~cm}$ diameter, $12.5 \mathrm{~cm}$ high), with a funnelled entrance $(3 \mathrm{~cm}$ diameter), beneath pointed cross vanes $(10 \mathrm{~cm}$ high) with a circular lid $(16.5 \mathrm{~cm}$ diameter) over the top. The bucket was filled with $500-700 \mathrm{ml}$ water containing $0.1 \%$ Triton X-100 to reduce the surface tension and drown insects falling through the funnel. In tests in strawberry, cross-vanes were green and in tests in raspberry they were white, acting as a visual attractant for B. tomentosus.

Parallel work on trap design in strawberry showed the Unitrap with green cross vanes to be more effective than other designs of trap (Fountain et al., 2017). The white colour attracted bees, thus a bee excluder grid above the funnel entrance that allows bees to fly off the trap was used (Trandem et al., 2009; Baroffio and Mittaz, 2010). Traps were placed on the ground among plants and secured by a bent welding rod (Wibe et al., 2014b) or hung $50 \mathrm{~cm}$ above ground on a wooden pole in some raspberry experiments. Traps were emptied and the water renewed every 14 days, at the same time removing foliage entangled in the vanes. Traps were renewed each year to avoid contamination from lures used in the previous year.

\subsection{Semiochemical lures}

Dispensers with sachets or polyethylene vials containing semiochemicals targeting each species individually were fastened under the 
Table 1

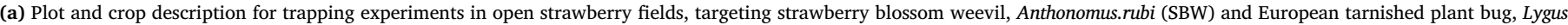

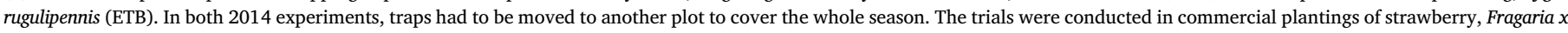

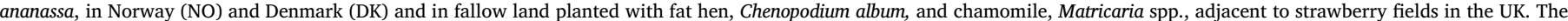

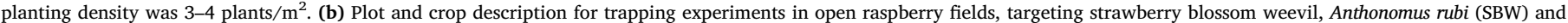
raspberry beetle, Byturus tomentosus (RB). The trials in raspberry were conducted in Norway (NO) and Switzerland (CH) with a plant density of 3 plants/m. ${ }^{2}$.

\begin{tabular}{|c|c|c|c|c|c|c|c|c|}
\hline Target species & Year of test & Country & Location & Variety & Planting year & Production $^{\mathrm{a}}$ & Plot size $\left(\mathrm{m}^{2}\right)^{\mathrm{b}}$ & Trapping period \\
\hline \multicolumn{9}{|l|}{ (a) Strawberry } \\
\hline ETB & 2013 & UK & East Malling & Clery & 2011 & $\mathrm{C}$ & 22,000 & $08.08-21.08$ \\
\hline SBW & 2013 & NO & Hedmarksbaer & Florence & 2009 & $\mathrm{C}$ & 6000 & $14.05-20.08$ \\
\hline SBW & 2013 & DK & Ventegodtgaard & Florence & 2011 & $\mathrm{O}$ & 6000 & $15.05-07.08$ \\
\hline SBW/ETB & 2014 & DK & Ventegodtgaard & Florence & 2011 & $\mathrm{O}$ & 6000 & $28.04-24.06$ \\
\hline SBW/ETB & 2014 & DK & Hyldagergaard & Florence & 2012 & $\mathrm{C}$ & 6000 & $25.06-16.09$ \\
\hline SBW/ETB & 2014 & DK & Saxebol & Mix & 2011 & $\mathrm{C}$ & 6100 & $23.04-04.06$ \\
\hline $\begin{array}{l}\text { SBW/ETB } \\
\text { (b) Raspberry }\end{array}$ & 2014 & NO & Huseby & Korona & 2011 & $\mathrm{C}$ & 6350 & $8.7-21.08$ \\
\hline SBW/RB & 2013 & $\mathrm{CH}$ & Nendaz & Glen Ample & 2006 & IP & 4500 & 24.04-11.09 \\
\hline SBW/RB & 2013 & NO & Nesjastranda & Glen Ample & 2010 & $\mathrm{C}$ & 6500 & $05.06-28.08$ \\
\hline SBW/RB & 2014 & $\mathrm{CH}$ & Salins & Glen Ample & 2004 & IP & 3500 & $16.04-30.07$ \\
\hline SBW/RB & 2014 & NO & Hedmarksbaer & Glen Ample & 2010 & $\mathrm{C}$ & 2000 & $28.05-03.09$ \\
\hline
\end{tabular}

${ }^{\text {a }}$ Production type: $\mathrm{C}=$ conventional; O: organic., IP: integrated production.

${ }^{\mathrm{b}}$ Not including neighbouring plots with other planting date or cultivar.

trap lid. For attracting $A$. rubi, the traps were baited with commercially available sachets (IPS International Pheromone Systems Ltd., Wirral, UK) containing $100 \mu \mathrm{l}$ of a 1:4:1 blend of cis-1-methyl-2-(1-methylethenyl)-cyclobutaneethanol (grandlure 1): (Z)-2-(3,3-dimethylcyclohexylidene)ethanol (grandlure 2): 5-methyl-2-(1-methylethenyl)-4hexen-1-ol (lavandulol) (Innocenzi et al., 2001; Cross et al., 2006a). For experimental purposes, vials contaning $100 \mathrm{mg}$ of the strawberry flower volatile, 1,4 dimethoxybenzene (DMB-high) (Wibe et al., 2014a) were added to the commercial lures. The release rates of the different compounds were: grandlure $1 ; 16 \mu \mathrm{g} / \mathrm{d}$, grandlure $2 ; 86 \mu \mathrm{g} / \mathrm{d}$, lavandulol; $47 \mu \mathrm{g} / \mathrm{d}$ and DMB; $666 \mu \mathrm{g} / \mathrm{d}$. All release rates were measured by trapping volatiles on Porapak resin and quantitative analysis by gas chromatography (c.f. Fountain et al., 2014). Also tested were lures containing the DMB in a polyethylene vial in the sachet which released the DMB at $68 \mu \mathrm{g} / \mathrm{d}$ (DMB-low). All lures were renewed every 8 weeks.

For L. rugulipennis the pheromone lure was a $1 \mathrm{ml}$ pipette tip containing $10 \mathrm{mg}$ hexyl-butyrate, $0.3 \mathrm{mg}(E)$-2-hexenyl butyrate and $2 \mathrm{mg}$ (E)-4-oxo-2-hexenal in $100 \mu$ l sunflower oil on a cigarette filter as described by Fountain et al. (2014). The three components were released in proportion to their initial loading with the release rate of hexyl butyrate from the pipette tip of $0.93 \pm 0.05$ (S.E.) $\mu \mathrm{g} / \mathrm{hr}$ at $27^{\circ} \mathrm{C}$ (Fountain et al., 2014). The host-plant volatile phenyl acetaldehyde (PAA) was formulated as $1 \mathrm{ml}$ on a dental roll in a polyethylene sachet $(5 \mathrm{~cm} \times 5 \mathrm{~cm} \times 250 \mu \mathrm{m}$ thick) made by heat-sealing layflat tubing (Transpack, Southampton, UK). The release rate of PAA from these sachets was $6 \mathrm{mg} / \mathrm{d}$ at $22^{\circ} \mathrm{C}$ as measured by weight loss. Both lures were prepared at the Natural Resources Institute (NRI) and were renewed every 4 weeks in field tests.

For B. tomentosus commercially available lures were used (Sentomol Ltd, Monmouth, UK) containing $2 \mathrm{~g}$ of the raspberry flower volatile blend (RV). The release rate of $\mathrm{RV}$ from these lures was $70 \mathrm{mg} / \mathrm{d}$ (Woodford et al., 2003; Birch et al., 2009). These lures were renewed every 6-8 weeks.

\subsection{Experimental design}

All experiments were run twice, one time in each of two countries, with the exception of the $2013 \mathrm{~L}$. rugulipennis experiment which was run once in the UK. Each experiment consisted of 5-7 lure combinations with 5-7 replicates tested in a completely randomized block design where plant rows were used as blocks. Distances between traps were approximately $10 \mathrm{~m}$. In all experiments, traps were emptied every 14 days and the catches were brought to the laboratory for identification and separated by sex when possible. In the 2014 strawberry experiments, the traps at both sites had to be moved to another plot in midsummer because the growers wanted to remove plants after harvest.

In the Swiss 2013 raspberry experiments, damage by $A$. rubi was determined by examining 20 inflorescences for cut buds within a $5 \mathrm{~m}$ radius of each trap from stage "flower begins" to stage " $30 \%$ flowers open" (stage BBCH 60-63) (Schmid et al., 2001). Damage by B. tomentosus was also evaluated by counting signs of larval feeding in four random fruits picked around each trap (4 fruits $\times 6$ traps $\times 5$ lure combinations $=120$ fruits) three times, at the beginning of harvest, mid-harvest and end of harvest (360 fruits in total).

\subsection{Statistical analyses}

To analyse the relative attractiveness of the different lures we used the proportion of total number of individuals of a species captured by each trap during the whole season. This method was chosen since samples sizes were often too small to include individual sampling dates in the analyses. In addition, Wibe et al. (2014a) showed that the capture proportions by different lures did not change throughout the season, and this procedure allowed comparisons independent of insect densities which varied between different fields.

Analysis of the effect of treatment on capture proportions was done using a generalized mixed model with a binomial distribution, except for UK data from 2013, which were analysed as number of insects trapped and the best model fit for $L$. rugulipennis data was obtained assuming a Poisson distribution. A Chi-square test or an analysis of deviance was used to test for significant effects of treatments in both types of distribution. Fixed parameters were treatment and country. Random variable in the models was block, and in the analysis of the 2014 trials in strawberries, site was included as a random variable because site and consequently also block were changed during the experiment. The models were reduced by removing non-significant interactions between country and lure. Comparisons of individual treatments were done by pairwise comparisons of means with $P$ values adjusted by the Tukey method (Lenth, 2016). All statistical analyses were performed using R, version 3.1.1 (R Development Core Team, 2012).

The sex ratio of $A$. rubi and $L$. rugulipennis caught per treatment was calculated by dividing the number of females by the total number of sexed specimens in each individual trap within the same treatment. A few insects could not be sexed, and were thus excluded from the analysis. 
Table 2

Catches of strawberry blossom weevil, Anthonomus rubi (SBW) and European tarnished plant bug, Lygus rugulipennis (ETB) in strawberry experimental plots in Denmark, Norway and in the UK during 2013. SBW $\mathrm{ph}=$ Anthonomus rubi aggregation pheromone; ETB $\mathrm{ph}=$ Lygus rugulipennis sex pheromone; DMB-high = 1,4-dimethoxybenzene high release rate; DMB- low = 1,4-dimethoxybenzene low release rate; PAA = phenylacetaldehyde; $\mathrm{RV}=$ raspberry flower volatile blend. $N=$ total catch in experiment. Different letters indicate statistically significant differences in relative capture between the treatments in an experiment (Tukey method, $P<0.05$ ).

\begin{tabular}{|c|c|c|c|c|}
\hline Treatment & $\begin{array}{l}\text { Total } \\
\text { catch }\end{array}$ & $\begin{array}{l}\text { Relative } \\
\text { proportion (\%) }\end{array}$ & $\begin{array}{l}\text { Total } \\
\text { catch }\end{array}$ & $\begin{array}{l}\text { Relative } \\
\text { proportion (\%) }\end{array}$ \\
\hline \multicolumn{5}{|c|}{ Anthonomus rubi (SBW) } \\
\hline & \multicolumn{2}{|c|}{ Denmark $2013(N=650)$} & \multicolumn{2}{|c|}{ Norway $2013(N=659)$} \\
\hline $\begin{array}{l}\text { SBW ph + DMB- } \\
\text { high }\end{array}$ & 184 & $28 \mathrm{a}$ & 107 & $16 \mathrm{a}$ \\
\hline RV & 14 & $2 \mathrm{c}$ & 37 & $6 \mathrm{~b}$ \\
\hline $\begin{array}{c}\text { SBW ph + DMB- } \\
\text { high }+ \text { RV }\end{array}$ & 142 & $22 \mathrm{a}$ & 140 & $21 \mathrm{a}$ \\
\hline DMB-high + RV & 32 & $5 \mathrm{c}$ & 135 & 20 a \\
\hline $\mathrm{SBW}$ ph $+\mathrm{RV}$ & 83 & $13 \mathrm{~b}$ & 99 & 15 a \\
\hline SBW ph + DMB-low & 195 & $30 \mathrm{a}$ & 141 & $21 \mathrm{a}$ \\
\hline \multicolumn{5}{|c|}{ Lygus rugulipennis (ETB) } \\
\hline & \multicolumn{2}{|c|}{ UK $2013(N=1545)$} & & \\
\hline DMB-high & 90 & $6 \mathrm{~d}$ & & \\
\hline DMB-high + PAA & 238 & $15 \mathrm{~b}$ & & \\
\hline $\begin{array}{l}\text { ETB ph + DMB- } \\
\text { high + PAA }\end{array}$ & 411 & $27 \mathrm{a}$ & & \\
\hline ETB ph + DMB-high & 154 & $10 \mathrm{c}$ & & \\
\hline PAA & 223 & $14 \mathrm{~b}$ & & \\
\hline ETB ph + PAA & 206 & $13 \mathrm{bc}$ & & \\
\hline ETB ph & 223 & $14 \mathrm{~b}$ & & \\
\hline
\end{tabular}

\section{Results}

\subsection{Strawberry}

For the experiments on A. rubi in strawberry during 2013 in Norway and Denmark, there was a significant effect of treatment and an interaction between country and treatment (Chi-square $=106.9$, $\mathrm{df}=5$, $P<0.001$ ) (Table 2). The three lures with significantly higher catches in both countries contained the $A$. rubi aggregation pheromone combined with plant volatile DMB at low or high release rates. A chi-square comparison of the number of $A$. rubi caught in the two treatments with A. rubi aggregation pheromone + DMB-high (SBW-Ph + DMB high and $\mathrm{SBW}-\mathrm{Ph}+\mathrm{DMB}$ high $+\mathrm{RV}$ ) and the treatment with A. rubi aggregation pheromone + DMB-low, showed a significantly higher catch with DMB-low in both Denmark (Chi-square $=4.60, \mathrm{df}=1, P=0.032$ ) and Norway (Chi-square $=160.00$, $\mathrm{df}=1, P<0.0001$ ). The lures attracted predominantly males, although some females were also trapped (Chi-square $=49.55, \mathrm{df}=5, P<0.001$ ) (Table 3).

For the experiment on $L$. rugulipennis in strawberry in the UK during 2013, treatment had a significant effect on catches (Chisquare $=255.39, \mathrm{df}=6, P<0.001)$ (Table 2). The lure combination with the $L$. rugulipennis sex pheromone with plant volatiles PAA and DMB- high was the most attractive and significantly more attractive than the $L$. rugulipennis sex pheromone alone or in combination with either DMB or PAA, or the two plant volatiles separately or combined. Lures with one or two plant volatiles trapped more females than males, whereas the $L$. rugulipennis sex pheromone alone caught predominantly males, as expected (Chi-square $=37.027, \quad \mathrm{df}=6, \quad P<0.001$ ) (Table 4).

When lures for $A$. rubi and L. rugulipennis were combined in the same trap during 2014, there were no significant interactions between the attractants for the two species and there were significant effects of treatment on catches for both species in both countries (A.rubi: Chisquare $=191.6, \quad \mathrm{df}=6, \quad \mathrm{P}<0.001 ; \quad$ L. $\quad$ rugulipennis: $\quad$ Chisquare $=23.475 \mathrm{df}=6, \mathrm{P}<0.001$ (Fig. 1). For example, in both Denmark and Norway, adding the $L$. rugulipennis sex pheromone to the
Table 3

Sex ratio in catches of strawberry blossom weevil, Anthonomus rubi (SBW), in traps with treatments targeting this species in strawberry in 2013 and 2014. SBW ph $=$ Anthonomus rubi aggregation pheromone; ETB $\mathrm{ph}=$ Lygus rugulipennis sex pheromone; DMB high $=1$,4-dimethoxybenzene high release rate; DMB-low $=1$,4-dimethoxybenzene low release rate; PAA = phenylacetaldehyde; $\mathrm{RV}=$ raspberry flower volatile blend. Danish and Norwegian data in 2013 pooled as no significant country effect. For 2014, data are presented for each country and there were no significant differences. Unsexed specimens not included. Different letters indicate significantly different percentage of females (Tukey method, $P<0.05$ )

\begin{tabular}{|c|c|c|c|c|}
\hline \multirow[t]{2}{*}{ Treatment } & \multicolumn{4}{|c|}{ Catch of Anthonomus rubi (SBW) } \\
\hline & Total & $\%$ Female & Total & $\%$ Female \\
\hline \multicolumn{5}{|l|}{2013} \\
\hline & \multicolumn{2}{|c|}{ Denmark and Norway } & & \\
\hline SBW ph + DMB-high & 291 & $22 \mathrm{bc}$ & & \\
\hline RV & 51 & $43 \mathrm{ab}$ & & \\
\hline SBW ph + DMB-high + RV & 282 & $29 \mathrm{bc}$ & & \\
\hline DMB-high + RV & 167 & $52 \mathrm{a}$ & & \\
\hline SBW ph + RV & 182 & $20 \mathrm{c}$ & & \\
\hline \multirow{2}{*}{$\begin{array}{l}\text { SBW ph + DMB-low } \\
2014\end{array}$} & 336 & $23 \mathrm{c}$ & & \\
\hline & \multicolumn{2}{|c|}{ Denmark } & \multicolumn{2}{|c|}{ Norway } \\
\hline SBW ph + DMB-low & 80 & 13 & 76 & 30 \\
\hline $\mathrm{ETB}$ ph + PAA & 5 & 100 & 34 & 29 \\
\hline $\mathrm{ETB}$ ph + DMB-low + PAA + RV & 9 & 33 & 56 & 38 \\
\hline ETB ph + DMB-low + PAA & 13 & 38 & 77 & 43 \\
\hline SBW ph + ETB ph + DMB-low & 117 & 15 & 63 & 33 \\
\hline $\mathrm{SBW}$ ph $+\mathrm{ETB} \mathrm{ph}+\mathrm{PAA}$ & 28 & 39 & 183 & 39 \\
\hline $\begin{array}{l}\text { SBW ph + ETB ph + DMB- } \\
\text { low + PAA }\end{array}$ & 62 & 32 & 196 & 35 \\
\hline
\end{tabular}

Table 4

Sex ratio in catches of European tarnished plant bug, Lygus rugulipennis (ETB), in traps with treatments targeting this species in strawberry in 2013 and 2014. SBW $\mathrm{ph}=$ Anthonomus rubi aggregation pheromone; $\mathrm{ETB} \mathrm{ph}=$ Lygus rugulipennis sex pheromone; DMB-high =1,4-dimethoxybenzene high release rate; DMB-low $=1$,4-dimethoxybenzene low release rate; PAA = phenylacetaldehyde; $\mathrm{RV}=$ raspberry flower volatile blend. Danish and Norwegian data in 2014 pooled as no significant country effect. Unsexed specimens not included. Different letters indicate significantly different percentage of females (Tukey method, $P<0.05$ ).

\begin{tabular}{lll}
\hline & \multicolumn{2}{l}{ Catches of Lygus rugulipennis (ETB) } \\
\hline Treatment & Total catch & $\%$ Female \\
\hline UK 2013 & & \\
DMB-high & 90 & $54 \mathrm{ab}$ \\
DMB-high + PAA & 238 & $72 \mathrm{a}$ \\
ETB ph + DMB-high + PAA & 411 & $62 \mathrm{a}$ \\
ETB ph + DMB-high & 154 & $40 \mathrm{a}$ \\
PAA & 223 & $69 \mathrm{a}$ \\
ETB ph + PAA & 206 & $52 \mathrm{a}$ \\
ETB ph & 223 & $23 \mathrm{~b}$ \\
Denmark and Norway 2014 & & \\
SBW ph + DMB-low & 42 & $62 \mathrm{a}$ \\
ETB ph + PAA & 319 & $15 \mathrm{bc}$ \\
ETB ph + DMB-low + PAA + RV & 362 & $25 \mathrm{~b}$ \\
ETB ph + DMB-low + PAA & 468 & $24 \mathrm{~b}$ \\
SBW ph + ETB ph + DMB-low & 457 & $6 \mathrm{~d}$ \\
SBW ph + ETB ph + PAA & 340 & $11 \mathrm{c}$ \\
SBW ph + ETB ph + DMB-low + PAA & 380 & $18 \mathrm{bc}$ \\
\hline
\end{tabular}

A. rubi aggregation pheromone + DMB- low dose combination caused no significant change in catches of $A$. rubi. Similarly, addition of the $A$. rubi aggregation pheromone to the combination of $L$. rugulipennis sex pheromone + PAA caused no significant change in catch rates of $L$. rugulipennis (Fig. 1). In Denmark the most attractive lure for both species was the combination of $A$. rubi aggregation pheromone + DMB-low dose + L. rugulipennis sex pheromone (Fig. 1a). In Norway, this combined lure was also very attractive to both species. Somewhat unexpectedly, in all cases addition of PAA seemed to further increase 
(a) Denmark

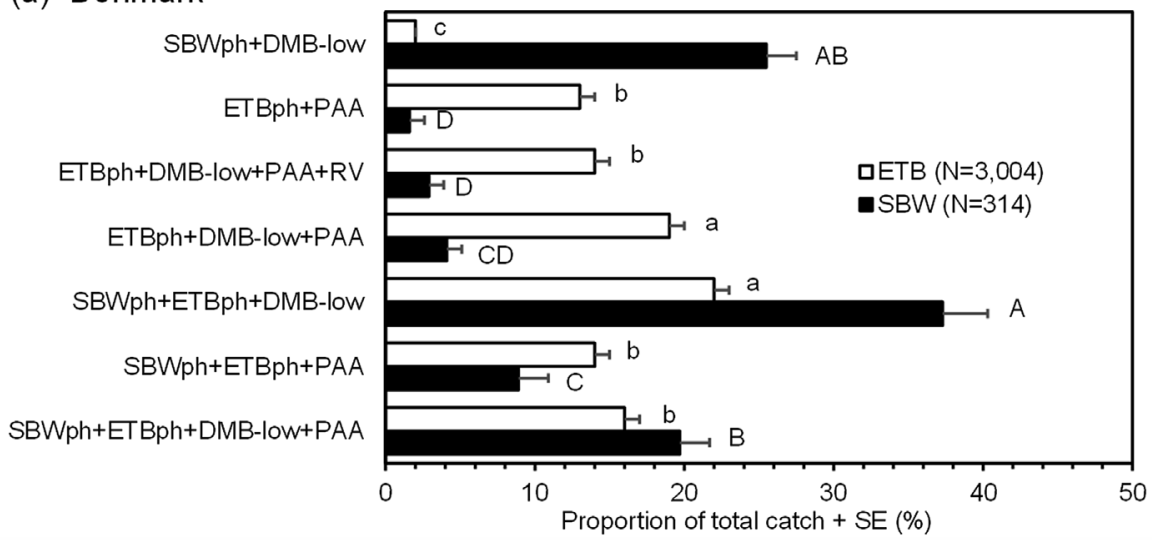

(b) Norway

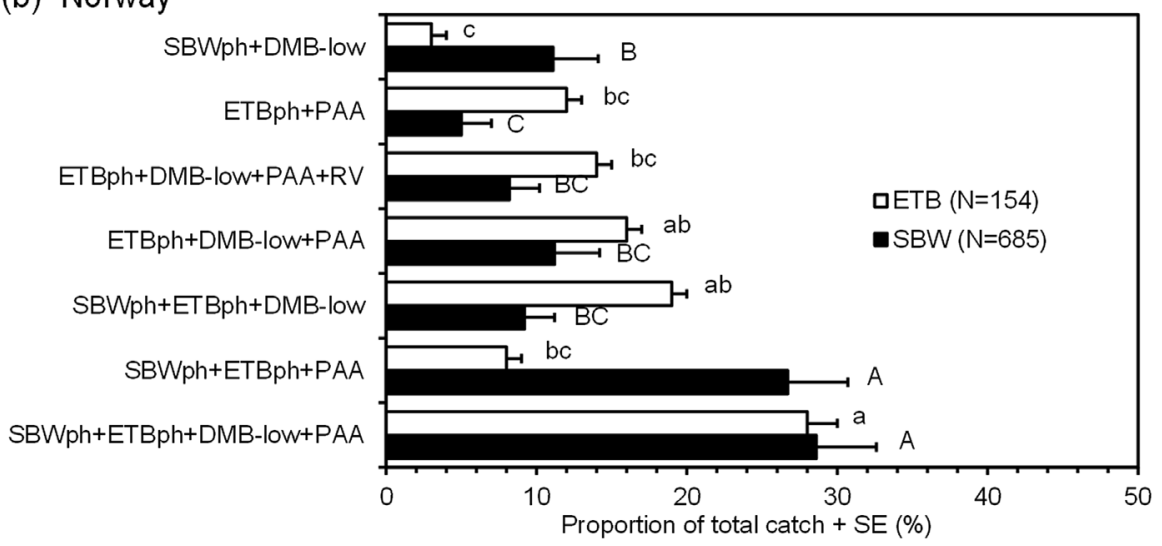

Fig. 1. Proportion of total trap catches (\%) of strawberry blossom weevil, Anthonomus rubi (SBW) and European tarnished plant bug, Lygus rugulipennis (ETB), in strawberries in (a) Denmark and (b) Norway in 2014 with seven lure blends. SBWph = Anthonomus rubi aggregation pheromone; ETBph $=$ Lygus rugulipennis sex pheromone; DMBhigh $=1$,4-dimethoxybenzene high release rate; DMBlow $=1$,4-dimethoxybenzene low release rate; PAA $=$ phenylacetaldehyde. Capital letters indicate differences between treatments for $A$. rubi, lower case letters indicate differences between treatments for L. rugulipennis (Tukey method, $P<0.05$ ). catches of $A$. rubi (Fig. 1b).

In most cases there were more males than females in catches of $A$. rubi, except where overall catches were very low (Table 3). Traps baited with lures containing the $L$. rugulipennis sex pheromone caught predominantly male $L$. rugulipennis even with addition of the plant volatiles PAA and DMB (Chi-square $=103.3, \mathrm{df}=6, P<0.001$ ) (Table 4).

\subsection{Raspberry}

In the experiments to catch $A$. rubi and $B$. tomentosus in the same trap in Norway and Switzerland during 2013, there was no country effect, thus the catch data were pooled. Presence of the A. rubi aggregation pheromone was essential for attraction of $A$. rubi, and addition of the raspberry flower volatile (RV) attractant for B. tomentosus actually increased catches of $A$. rubi (Chi-square $=188.89$, $\mathrm{df}=4$, $P<0.001$ ) (Fig. 2a). There was no effect of lure combination on the sex ratio in the catches (Chi-square $=14.59 \mathrm{df}=9, P=0.1028$ ) with the two most attractive lures attracting $47 \%$ and $50 \%$ females.

For catches of $B$. tomentosus presence of the raspberry flower volatile (RV) was essential, and the one combination without this compound caught significantly fewer beetles (Chi-square $=49.55, \mathrm{df}=4$, $P<0.001$; Fig. 2a).

During 2013, the number of inflorescences damaged by $A$. rubi within $5 \mathrm{~m}$ of the trap was not influenced by attractants (KruskalWallis: 0.4, $P=0.91$; data not shown). For fruit containing larvae of $B$. tomentosus a general linear analysis comparison of treatments on proportion damaged berries showed no effect of treatments or harvest time ( $\mathrm{F}=2.15, \mathrm{df}=4.8, P=0.17$ and $\mathrm{F}=1.59$, $\mathrm{df}=2,8, P=0.26$, respectively), but a contrast comparison of the combination of $A$. rubi aggregation pheromone and raspberry flower volatile against all other treatments was near significant $(\mathrm{F}=4.76, \mathrm{df}=1.8, P=0.061)$. The combination of $A$. rubi aggregation pheromone and raspberry flower volatile was also the treatment that only showed damage at the end of harvest (Fig. 3).

In 2014, the catches were generally lower (Fig. 2b) and there was no effect of country or lure on the catches of $A$. rubi (Chi-square $=0.1646$, $\mathrm{df}=1, \mathrm{P}=0.685$ ) or the proportion of females (Analysis of Deviance: deviance $=9.904, \mathrm{df}=11, P=0.539$ ) with the two most attractive lures catching $57 \%$ and $60 \%$ females. There was an interaction between effect of lures and effect of country on B. tomentosus (Chisquare $=34.672, \mathrm{df}=3, P<0.001$; Fig. 2b). There was no effect of lures on catches of $B$. tomentosus in Switzerland. In Norway the combination of $A$. rubi aggregation pheromone + raspberry flower volatile was significantly more attractive to $B$. tomentosus than all other treatments. However, captures were low and in this treatment one trap alone caught 111 B. tomentosus which was a significant outlier as146 beetles of this species was sampled altogether in the whole field.

\section{Discussion}

This study, carried out in four European countries and two berry crops, has shown that improvements can be made to existing semiochemical lures for two of the three main insect pests. Furthermore, they can be combined in traps, not only with no loss of attractiveness to the target pests, but in some cases even an increase in trap catch.

For $A$. rubi, addition of 1,4-dimethoxybenzene (DMB) to the commercially-available aggregation pheromone increased catches in Denmark and Norway, as previously reported (Wibe et al., 2014a). DMB is relatively cheap compared with the cost of the pheromone and addition of this would add little to the cost of the lure. Even so, it was also found that a lower release rate of DMB was at least as attractive as a higher release rate which would further minimise the extra cost. This result demonstrated the importance of blend ratios in attraction of insects to pheromones and host-plant volatiles (Bruce and Pickett, 2011) 
(a) 2013

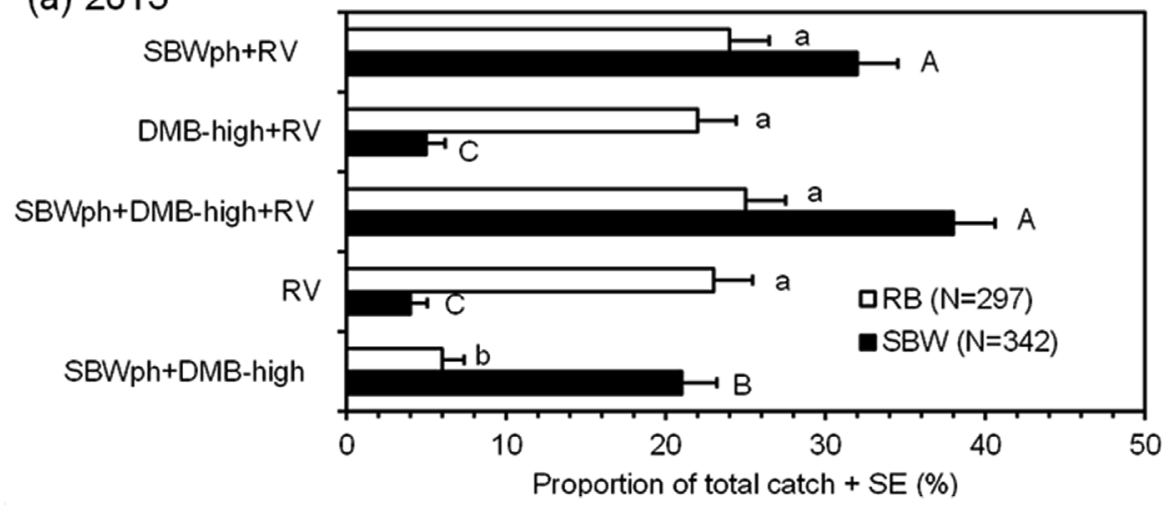

(b) 2014

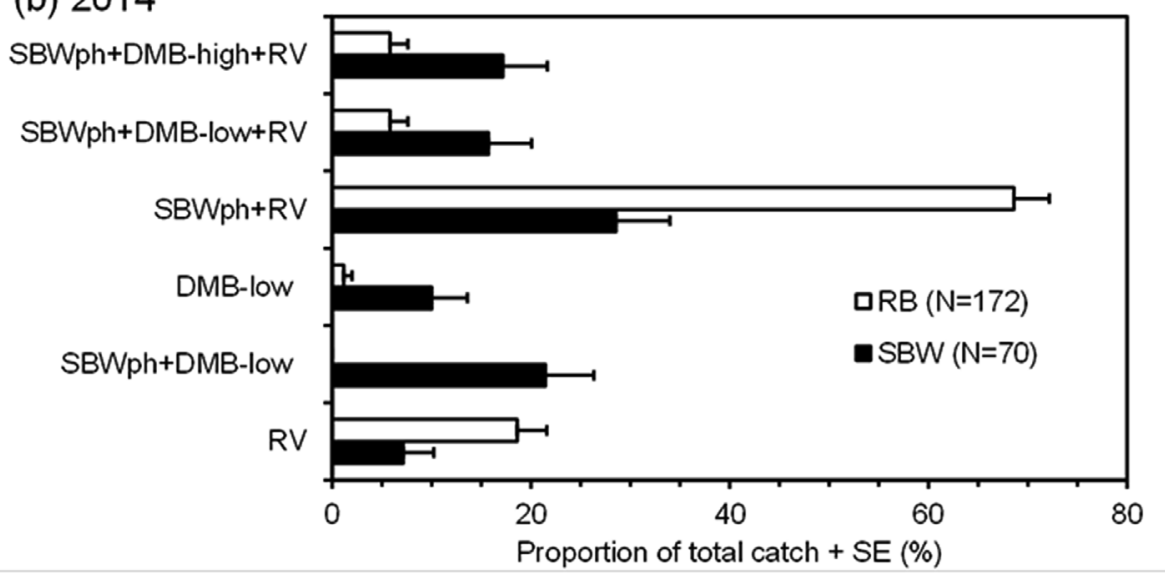

Fig. 2. Proportion of total trap catches of strawberry blossom weevil, Anthonomus rubi (SBW) and raspberry beetle, Byturus tomentosus (RB), in raspberries in Switzerland and Norway during (a) 2013 and (b) 2014. $\mathrm{SBWph}=$ Anthonomus rubi aggregation pheromone; DMBhigh $=1$,4-dimethoxybenzene high release rate; $\mathrm{RV}=$ raspberry flower volatile blend. Capital letters indicate differences between treatments for A. rubi (Tukey method, $P<0.05$ ), lower case letters indicate differences between treatments for $B$. tomentosus (Tukey method, $P<0.05)$

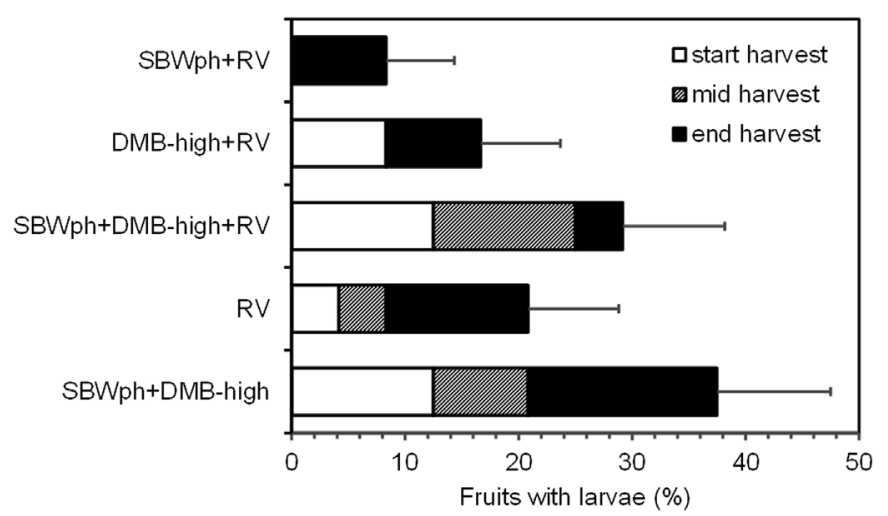

Fig. 3. Presence of larvae of Byturus tomentosus in raspberries during the harvest period in Switzerland during 2013. On each sampling occasion 120 berries were examined. SBW $\mathrm{ph}=$ Anthonomus rubi aggregation pheromone; $\mathrm{DMB}=$ 1,4-dimethoxybenzene; $\mathrm{RV}=$ raspberry flower volatile blend.

and indicates that further work to optimise the blends of pheromones and plant volatiles would be justified. However, the blend of raspberry volatiles (RV) was unattractive to $A$. rubi and addition of this to the aggregation pheromone had no effect on catches.

In strawberry in the UK, significantly higher catches of $L$. rugulipennis were obtained by adding plant volatiles phenylacetaldehyde (PAA) and the strawberry flower volatile (DMB) to the sex pheromone, and this was mainly due to increased catch of females which is important for use of these devices in both monitoring and control of the pest. This has previously been reported for addition of PAA alone (Frati et al., 2009; Koczor et al., 2012), but this is the first time an effect of the DMB has been shown. As with A. rubi, PAA and DMB are relatively cheap compared with the cost of the pheromone, and addition of either or both of these to the lure would not increase cost greatly.

When both $A$. rubi and $L$. rugulipennis were targeted for the same trap in strawberry, it was again found that combination of DMB at low dose with the $A$. rubi aggregation pheromone was more attractive than that with DMB at the higher dose. In Denmark, highest catches of both species were obtained with the blend of $A$. rubi aggregation pheromone, L. rugulipennis sex pheromone and DMB low dose. Addition of PAA gave lower catches in Denmark, but increased catches of both species in Norway, consistent with the results for the tests on L. rugulipennis only.

In raspberry during 2013, the blend of raspberry volatiles (RV) was a strong attractant for $B$. tomentosus and traps that did not contain this volatile captured few beetles, as found previously (Birch et al., 2009; Trandem et al., 2009; Baroffio and Mittaz, 2011; Baroffio et al., 2012). Catches of $A$. rubi in raspberries were highest with combinations of $A$. rubi aggregation pheromone and $\mathrm{DMB}$ with no differences between catches with DMB at the two release rates in this crop. Traps baited with the aggregation pheromone of $A$. rubi and the raspberry flower volatile blend, with or without the plant volatile DMB, attracted both $A$. rubi and $B$. tomentosus in the same trap, and no reduced attraction was observed in either species. In raspberries the different lures did not affect sex ratio for A. rubi, which across treatments was around $50 \%$.

In the raspberry experiments in 2014 there was no effect of lure on catches of $A$. rubi. There was a significant and positive effect of the combination of $A$. rubi aggregation pheromone $+\mathrm{RV}$ over all other treatments. However low captures and a significant outlier makes it difficult to interpret on the results from sampling in raspberry the second experimental year.

The present study shows that traps containing lures for the main insect pests of strawberry and raspberry can be used for monitoring these pests. This will not lead to confusion for the user as the targeted taxonomically unrelated species can be distinguished from each other by non-specialists. The main results were consistent across countries 
and seasons. Although the data were combined during each season there were no obvious changes in relative attractiveness of the lures during the season (data not shown but see Wibe et al., 2014a) and the lures were renewed well within their expected lifetime under field conditions. Parallel studies of trap design and placement by Fountain et al. (2017) have further optimized these parameters, and these traps can be used for standardised monitoring programmes. In adddition, the traps can be used to explore the relationships between trap catches and field populations and plant damage by L. rugulipennis (Xu et al., 2014).

However, the traps used here are probably not suitable for use in control by mass trapping (El-Sayed et al., 2006) or attract-and-kill (ElSayed et al., 2009) as they are relatively expensive and require regular maintenance to renew the insect drowning solution. Other work has also indicated that the traps are not very efficient in capturing insects attracted to the region of the traps, particularly for $\mathrm{A}$. rubi (unpublished). Nevertheless, there are some evidence that the presence of the traps baited with both the sex pheromone and host-plant volatiles at a density of 50 per ha reduced damage by L. rugulipennis on an experimental scale (Fountain et al., 2015, 2017), and further work is required to develop simpler trapping devices or attract-and-kill systems with an insecticide or biological control agent which can be used in combination with the lures developed here.

\section{Acknowledgements}

The authors gratefully acknowledge the financial support for the project "Softpest Multitrap" provided by the CORE Organic II Funding Bodies, being partners of the FP7 ERA-Net project, CORE Organic II (Coordination of European Transnational research in Organic Food and Farming systems, project no. 249667). For further information see: www.coreorganic2.org. The text in this report is the sole responsibility of the authors and does not necessarily reflect the view of the national funding bodies having financed this project. We thank Jørn Haslestad, Paolo Rendina, Pauline Richoz, Aude Rogivue, Peter WedervangJensen, Marta Montoro Caceres and Kristian Hansen for their help with the field work, Dudley Farman (NRI) for assistance with preparation of lures.

\section{References}

Aasen, S.S., Trandem, N., 2006. Strawberry blossom weevil Anthonomus rubi Herbst (Col. Curculionidae): relationships between bud damage, weevil density, insecticide use, and yield. J. Pestic. Sci. (Noyaku Kaguku) 79, 169-174.

Alpizar, D., Fallas, M., Oelschlager, A., Gonzalez, L., Chinchilla, C., Bulgarelli, J., 2002 Pheromone mass trapping of the West Indian sugarcane weevil and the American palm weevil (Coleoptera: Curculionidae) in palmito palm. Fla. Entomol. 85, 426-430.

Antonin, P., 1984. Le ver des framboises, Byturus tomentosus. Rev. Suisse Vitic. Arboric. Hortic. 16, 103-105.

Baroffio, C., Mittaz, C., 2010. Byturus tomentosus, raspberry beetle flight monitoring and controlling with semiochemical traps. IOBC-WPRS Bull. 54, 397-400.

Baroffio, C., Mittaz, C., 2011. Pièges attractifs floraux dans la lutte contre le ver des framboises. Rev. Suisse Vitic. Arboric. Hortic. 43, 106-112.

Baroffio, C., Trandem, N., Birch, A.N.E., 2012. Efficiency of attractive traps in the fight against Byturus tomentosus in raspberries: examples from Switzerland, Scotland and Norway. IOBC-WPRS Bull. 946, 213-217.

Birch, A.N.E., Gordon, S., Shepherd, T., Griffith, W., Robertson, G., Brennan, R., 2009. Development of semiochemical attractants, lures and traps for raspberry beetle, Byturus tomentosus at SCRI; from fundamental chemical ecology to testing IPM tools with growers. IOBC-WPRS Bull. 41, 75-78.

Bruce, T.J.A., Pickett, J.A., 2011. Perception of plant volatile blends by herbivorous insects - finding the right mix. Phytochemistry 72, 1605-1611.

Cai, X., Bian, L., Xu, X., Luo, Z., Li, Z., Chen, Z., 2017. Field background odour should be taken into account when formulating a pest attractant based on plant volatiles. Sci. Rep. 7.

Cross, J., Berrie, A., 2006. The challenges of developing IPM programmes for soft fruit crops that eliminate reportable pesticide residues. J. Fruit Ornam. Plant Res. 14, 49.

Cross, J., Fountain, M., Hall, D., 2011. Management of European tarnished plant bug in late seasons strawberries. IOBC-WPRS Bull. 70, 170.

Cross, J., Hall, D., Innocenzi, P., Burgess, C., 2004. Exploiting the sex-aggregation pheromone of strawberry blossom weevil (Anthonomus rubi). IOBC-WPRS Bull. 27, $125-132$.

Cross, J.V., Hesketh, H., Jay, C.N., Hall, D.R., Innocenzi, P.J., Farman, D.I., Burgess, C.M., 2006a. Exploiting the aggregation pheromone of strawberry blossom weevil
Anthonomus rubi Herbst (Coleoptera: Curculionidae): Part 1. Development of lure and trap. Crop Protect. 25, 144-154.

Cross, J.V., Hall, D.R., Innocenzi, P.J., Hesketh, H., Jay, C.N., Burgess, C.M., 2006b. Exploiting the aggregation pheromone of strawberry blossom weevil Anthonomus rubi (Coleoptera : Curculionidae): Part 2. Pest monitoring and control. Crop Protect. 25, $155-166$.

Easterbrook, M., Fitzgerald, J., Pinch, C., Tooley, J., Xu, X.-M., 2003. Development times and fecundity of three important arthropod pests of strawberry in the United Kingdom. Ann. Appl. Biol. 143, 325-331.

El Sayed, A., Suckling, D., Wearing, C., Byers, J., 2006. Potential of mass trapping for long term pest management and eradication of invasive species. J. Econ. Entomol. 99, 1550-1564.

El Sayed, A., Suckling, D., Byers, J.A., Jang, E.B., Wearing, C., 2009. Potential of "lure and kill" in long-term pest management and eradication of invasive species. J. Econ. Entomol. 102, 815-835.

Fitzgerald, J.D., Jay, C.N., 2011. Chemical control of the European tarnished plant bug, Lygus rugulipennis, on strawberry in the UK. Crop Protect. 30, 1178-1183.

Fountain, M., Jastad, G., Hall, D., Douglas, P., Farman, D., Cross, J., 2014. Further studies on sex pheromones of female Lygus and related bugs: development of effective lures and investigation of species-specificity. J. Chem. Ecol. 40, 71-83.

Fountain, M., Shaw, B., Trandem, N., Storberget, S., Baroffio, C., Ralle, B., Rendina, P., Richoz, P., Sigsgaard, L., Borg-Karlson, A.-K., Hall, D.R., Cross, J.V., Wibe, A., 2015 The potential of mass trapping Lygus rugulipennis and Anthonomus rubi; trap design and efficacy. IOBC-WPRS Bull. 109, 95-97.

Fountain, M., Baroffio, C., Borg-Karlson, A.-K., Brain, P., Cross, J., Farman, D., Hall, D., Ralle, B., Rendina, P., Richoz, P., Sigsgaard, L., Storberget, S., Wibe, A., 2017. Design and deployment of semiochemical traps for capturing Anthonomus rubi Herbst (Coleoptera: Curculionidae) and Lygus rugulipennis Poppius (Heteroptera: Miridae) in soft fruit crops. Crop Protect. 99, 1-9.

Frati, F., Salerno, G.E., Conti, e, Bin, F., 2008. Role of plant-consepcific complex in host location and intra-specific communication of Lygus rugulipennis. Physiol. Entomol. 33, $129-137$.

Frati, F., Chamberlain, K., Birkett, M., Dufour, S., Mayon, P., Woodcock, C., Wadhams, L. Pickett, J., Salerno, G., Conti, E., Bin, F., 2009. Vicia faba - Lygus rugulipennis interactions: induced plant volatiles and sex pheromone enhancement. J. Chem. Ecol. 35, 201-208.

Hillocks, R.J., 2012. Farming with fewer pesticides: EU pesticide review and resulting challenges for UK agriculture. Crop Protect. 31, 85-93.

Innocenzi, P.J., Hall, D.R., Cross, J.V., 2001. Components of male aggregation pheromone of strawberry blossom weevil, Anthonomus rubi Herbst. (Coleoptera : Curculionidae). J. Chem. Ecol. 27, 1203-1218.

Innocenzi, P.J., Hall, D.R., Cross, J.V., Green, S.V., 2002. Sexing adults of the strawberry blossom weevil, Anthonomus rubi (Col., Curculionidae). J. Appl. Entomol. 126, $159-160$.

Innocenzi, P.J., Hall, D., Cross, J., Hesketh, H., 2005. Attraction of male European tarnished plant bug, Lygus rugulipennis to components of the female sex pheromone in the field. J. Chem. Ecol. 31, 1401-1413.

Knudsen, G.K., Norli, H.R., Tasin, M., 2017. The ratio between field attractive and background volatiles encodes host-plant recognition in a specialist moth. Front. Plant Sci. 8, 11. http://dx.doi.org/10.3389/fpls.2017.02206.

Koczor, S., Vuts, J., Toth, M., 2012. Attraction of Lygus rugulipennis and Adelphocoris lineolatus to synthetic floral odour compounds in field experiments in Hungary. J. Pest. Sci. 85, 239-245.

Landolt, P.J., Phillips, T., 1997. Host plant influences on sex pheromone behaviour of phytophagous insects. Annu. Rev. Entomol. 42, 371-391.

Lenth, R., 2016. Least-squares means: the R package lsmeans. J.Statistics Software 69 http://dx.doi.org/10.18637/jss.v069.i01.

Lindgren, B., 1983. A multiple funnel trap for scolytid beetles (Coleoptera). Can. Entomol. 115, 299-302.

Nakashima, Y., Ida, T., Powell, W., Pickett, J., Birkett, M., Taki, H., Takabayashi, J., 2016. Field evaluation of synthetic aphid sex pheromone in enhancing suppression of aphid abundance by their natural enemies. BioControl 61, 485-496.

Oelschlager, A., McDonald, R., Chinchilla, C., Patschke, S., 1995. Influence of a pheromone-based mass-trapping system on the distribution of Rynchophorus palmarum (Coeloptera : Curculionidae) in oil palm. Environ. Entomol. 24, 1005-1012.

Ridgway, R.L., Inscoe, M.N., Dickerson, W.A., 1990. Role of the boll weevil pheromone in pest mangement: 437-471. In: Ridgway, R.L., Silverstein, R.M., Inscoe, M.N. (Eds.) Behavior Modifying Chemicals for Insect Management. Marcel Dekker, New York.

Saïd, I., Renou, M., Morin, J.P., Ferreira, J., Rochat, D., 2005. Interactions between acetoin, a plant volatile, and pheromone in Rhynchosporum palmarum : behavioral and olfactory neuron responses. J. Chem. Ecol. 31, 1789-1805.

Schlyter, F., Zhang, Q., Liu, G., Ji, L., 2001. A successful case of pheromone mass trapping of the bark beetle Ips duplicatus in a forest island, analysed by a 20 -year time series data. Integrated Pest Manag. Rev. 6, 185-196.

Schmid, K., Höhn, H., Graf, B., Höpli, H.U., 2001. Phenological growth stages of raspberry (Rubus idaeus L.). Agrarforschung 8, 215-222.

Schmid, A., Höhn, H., Schmid, K., Weibel, F., Daniel, C., 2006. Effectiveness and side effects of glue-traps to decrease damages caused by Byturus tomentosus in raspberry. J. Pest. Sci. 79, 137-142.

Smit, N., Dowham, M., Odongo, B., Hall, D., Laboke, P., 1997. Development of pheromone traps for control and monitoring of sweetpotato weevils, Cylas puncticollis and C. brunneus, in Uganda. Entomol. Exp. Appl. 85, 95-104.

Stäubli, A., Höhn, H., 1989. Anthonome du fraisier et du framboisier Antonomus rubi Hbst. Vol. Fiche 017: by Agroscope.

Stenseth, C., 1974. The life cycle and phenology of Byturus tomentosus (Col., Byturidae) in Norway. Forskning og forsøk i landbruket 25, 191-199. 
Suckling, D., 2000. Issues affecting the use of pheromones and other semiochemicals in orchards. Crop Protect. 19, 677-683.

Tamm, L., Häseli, A.J.F., Weibel, F., Wyss, E., 2004. Organic fruit production in humid climates of Europe: bottlenecks and new approaches in disease and pest control. Acta Hortic. (Wagening.) 638, 333-339.

Tingle, F., Mitchell, E., 1975. Capture of Spodoptera frugiperda and S. exigua in pheromone traps. J. Econ. Entomol. 68, 613-615.

Trandem, N., Aasen, S., Hagvar, E., Haslestad, J., Salinas, S., Sonsteby, A., 2004. Strawberry blossom weevil-recent research in Norway. IOBC-WPRS Bull. 27, 145-152.

Trandem, N., Baroffio, C., Fountain, M., Ralle, B., Rendina, P., Richoz, P., Sigsgaard, L., Borg-Karlson, A.K., Hall, D.R., Cross, J.V., Wibe, A., 2015. Using semiochemical traps to study the occurence of strawberry blossom weevil in strawberry and raspberrywhat did we learn? IOBC-WPRS Bull. 109, 93-94.

Trandem, N., Gordon, S., Birch, A.N.E., Ekeland, M., Heiberg, N., 2009. Mass trapping of raspberry beetle as possible control method - pilot trial in Norway. IOBC-WPRS Bull. 39, 5-10.

Wang, F., Deng, J., Schal, C., Lou, Y., Zhou, G., Ye, B., Yin, X., Xu, Z., Shen, L., 2016. Nonhost plant volatiles disrupt sex pheromone communication in a specialist herbivore. Sci. Rep. 6.

Wibe, A., Apenite, I., Baroffio, C., Borg-Karlson, A.-K., Cross, J., Hall, D., Sigsgaard, L.,
Trandem, N., 2012. Management of strawberry blossom weevil and European tarnished plant bug in organic strawberry and raspberry using semiochemical traps. In: XXIV International Congress of Entomology, Daegu, Republic of Korea, 19-25 August.

Wibe, A., Borg-Karlson, A.K., Cross, J.V., Bichao, H., Fountain, M., Liblikas, M., Sigsgaard, L., 2014a. Combining 1,4-dimethoxybenzene, the major flower volatile of wild strawberry Fragaria vesca, with the aggregation pheromone of the strawberry blossom weevil Anthonomus rubi improves attraction. Crop Protect. 64, 122-128.

Wibe, A., Cross, J.V., Borg-Karlson, A.-K., Hall, D.R., Trandem, N., Sigsgaard, L., Baroffio, C., Ralle, B., Fountain, M.T., 2014b. Softpest multitrap - management of strawberry blossom weevil and European tarnished plant bug in organic strawberry and raspberry using semiochemical traps. Vol. 20: building Organic Bridges. In: Rahmann, G., Aksoy, U. (Eds.), Johann Heinrich von Thünen-Institut. Germany, Braunschweig, pp. 883-886.

Woodford, A.T., Birch, A.N.E., Gordon, S., Griffith, W., McNicol, J., Robertson, G., 2003. Controlling raspberry beetle without insecticide. Integrated plant production in orchards. IOBC-WPRS Bull. 26, 87-92.

Xu, X.-M., Jay, C.N., Fountain, M.T., Linka, J., Fitzgerald, J.D., 2014. Development and validation of a model forecasting the phenology of European tarnished plant bug Lygus rugulipennis in the U.K. Agric. For. Entomol. 16, 265-272. 